\title{
Evolving Perspectives on Lyme Borreliosis in Canada
}

\author{
J.L.H. Sperling ${ }^{1,2}$, M.J. Middelveen², D. Klein ${ }^{3}$, and F.A.H. Sperling*,1 \\ ${ }^{1}$ Department of Biological Sciences, University of Alberta, Edmonton, Canada \\ ${ }^{2}$ Canadian Lyme Disease Foundation, West Kelowna, British Columbia, Canada \\ ${ }^{3}$ Department of Family Medicine, University of Alberta, Edmonton, Canada
}

\begin{abstract}
With cases now documented in every province, Lyme borreliosis (LB) is emerging as a serious public health risk in Canada. Controversy over the contribution of LB to the burden of chronic disease is maintained by difficulty in capturing accurate Canadian statistics, especially early clinical cases of LB. The use of dogs as sentinel species demonstrates that potential contact with Borrelia burgdorferi spirochetes, as detected by C6 peptide, extends across the country. Dissemination of infected ticks by migratory birds and rapid establishment of significant levels of infection have been well described. Canadian public health response has focused on identification of established populations of the tick vectors, Ixodes scapularis and I. pacificus, on the assumption that these are the only important vectors of the disease across Canada. Strains of B. burgdorferi circulating in Canada and the full range of their reservoir species and coinfections remain to be explored. Ongoing surveys and historical records demonstrate that Borrelia-positive Ixodes species are regularly present in regions of Canada that have previously been considered to be outside of the ranges of these species in recent modeling efforts. We present data demonstrating that human cases of LB are found across the nation. Consequently, physician education and better early diagnoses are needed to prevent long term sequelae. An international perspective will be paramount for developing improved Canadian guidelines that recognize the complexity and diversity of Lyme borreliosis.
\end{abstract}

Keywords: Borrelia burgdorferi, chronic disease, Ixodes, public health, zoonotic disease.

\section{INTRODUCTION}

The ambiguity inherent in difficult-to-diagnose diseases is an underappreciated part of health policy landscapes worldwide, and such diseases represent an increasingly more polarized conundrum for health practitioners [1,2]. On the one hand, the rising cost of public health care has led to increasing demands for accountability and certainty in medical diagnoses, leaving medical understanding of diseases that have inherently uncertain diagnoses to wither for lack of statistical rigor and the kind of streamlined throughput that makes economic sense. On the other hand, our current medical system has been especially effective in reducing the burden of diseases with clear diagnoses, leaving an increasingly greater proportion of morbidity due to illnesses whose defining characteristics are uncertain. Lyme borreliosis (LB), also known as Lyme disease, is a particularly instructive example of the latter category.

In Canada, the diagnosis of LB has been the subject of much debate. Lack of definitive blood tests and disagreement over the role of clinical diagnoses have held back progress toward consensus on effective medical treatment, even though the paramount importance of early diagnosis for

*Address correspondence to this author at the Department of Biological Sciences, University of Alberta, Edmonton, Alberta, T6G 2E9 Canada;

Tel: 1-780-492-3991;Fax: (780) 492-9234;

E-mail: felix.sperling@ualberta.ca successful resolution of symptoms is well recognized [3-5]. Public statements by some professional organizations have stressed the rarity of LB in Canada, highlighting concerns with overdiagnosis and warning against overuse of antibiotics (e.g. [6,7]. A different view is voiced by patient support organizations in Canada that have documented concerns (e.g. [8] and mounted public demonstrations (e.g. $[9,10]$ to call attention to Lyme borreliosis across Canada.

\section{LYME BORRELIOSIS DIAGNOSTIC CRITERIA}

In Canada, Lyme disease has generally been divided into three stages [11]. Acute localized infection by Borrelia burgdorferi spirochetes is considered to be easy to cure in most cases with a short course of oral antibiotics. If untreated in this first stage, acute disseminated Lyme follows in weeks to months. This second stage is characterized by the spirochetes leaving the initial site of entry to infect other tissues, causing cardiac, neurological, or musculoskeletal symptoms. In the third stage, chronic disseminated LB develops months to years later, involving persistent symptoms particularly in skin, nervous system and joints [11]. The third stage of LB is the most controversial, both in terms of definition and treatment. Many physicians in North America (e.g. [12,13] believe that persistent infection by Borrelia is the cause of the disease processes that may follow acute LB, and that the later stages are more refractory to antibiotic treatment. Others ( e.g. $[14,15]$ have distinguished LB from an illness that they term post Lyme disease syndrome. The second group 
state that LB is characterized at all stages by a positive response to 28 days or less of antibiotics, after which antibiotic treatment should cease since post Lyme disease syndrome is not maintained by active Borrelia infection. At most, a second course of treatment can be considered for patients who relapse. The latter viewpoint on chronic LB is currently dominant in Canada [16].

Although the decision by a physician to treat LB in Canada may ultimately rest on a purely clinical diagnosis [17], in reality it is difficult to render such a diagnosis with confidence. Very few physicians in Canada have experience with $\mathrm{LB}$, and a major contributor to the difficulty of making clinical diagnoses is that a wide range of symptoms are associated with LB [18]. When otherwise healthy patients present a confusing array of symptoms to their primary care doctors, a diagnosis can be delayed due to the need for repeat visits and consultation with specialist physicians. Such a delay allows acute Lyme the opportunity to progress to a chronic stage at increased cost to the public health system.

It is now well recognized that chronic disease is a major contributor to health costs and diminished quality of life in Canada. This recognition has generated significant public interest and recent policy changes by the Public Health Agency of Canada [19], including an integrated strategy on healthy living and chronic disease that stresses cooperation among diverse partners and depends on international collaboration. However, there is little or no recognition of LB as a contributing factor to the overall burden of chronic illness in Canada.

\section{LYME BORRELIOSIS RATES IN CANADA}

In Canada, documented diagnosis of LB is rare, with approximately 50 cases per year for a population of 32 million in 2005 [20]. This compares to nearly 13000 cases per year in American states that are contiguous to Canada [21]. Canadian reports of LB disease incidence have relied on voluntary reporting, since national reporting of Lyme disease has only recently been established and no definitive national statistics are yet publicly available. The federal Public Health Agency of Canada considers the risk of contracting LB to be low but increasing [22], and research publications have documented increased risk of LB exposure in eastern Canada [4]. Other organizations such as the Canadian Paediatric Society [23] and the British Columbia Centre for Disease Control [24] state that disease rates over past decades have remained stable. Furthermore, the majority of recognized cases for Canada are considered to be travel related [20]. In British Columbia, a known endemic region, $40 \%$ of cases are nonetheless reported to be travel related, with most of these originating in European countries that have established endemicity for $B$. burgdorferferi sensu lato [25].

In order to be counted as a verified case of LB, Canadian statistics for acute cases rely on the presence of an erythema migrans (EM) rash that was contracted in an area known to be endemic for Lyme borreliosis [26]. For all other LB stages or cases from non-endemic areas, a serological response is required for a positive diagnosis [26]. Unfortunately, there is no consistent process for updating information about a region to allow practitioners to reliably consider it as endemic [25]. A positive serological response for $B$. burgdorferi is defined as a positive screening ELISA followed by a western blot with five of ten bands for IgG. For a positive IgM western blot, at least two of three bands are required for a positive diagnosis. A positive IgM western blot beyond six weeks after exposure is considered to be a false positive [26]. This definition is based on the American Centers for Disease Control (US CDC) definition and does not take into account the possibility of a renewed IgM response, as has been suggested for LB by Donta [12] and demonstrated for other diseases such as Ehrlichia [27]. The US CDC definition was revised in 2008 [28] and again in 2011 [29], but it is unclear which definition is followed in Canada now that the disease is nationally notifiable ( $c f$ [30-33]. ELISAs based on the C6 peptide antibody response have recently been licensed in Canada and may be requested by the ordering physician [3].

European strains of LB are not well detected by the serology currently used in Canada [34]. Since the majority of cases that are officially recognized are already believed to be travel related [20] this is cause for concern for travelers to Europe. Acute cases of Lyme disease contracted in European countries thus are at greater risk of progressing to later stages of LB that may be more difficult to treat and can result in chronic symptoms [35]. Recently, tests that are sensitive for European strains were added to the range of diagnostic options available at the Canadian national microbiology lab, although they must be specifically requested by the referring doctor [36].

The newly implemented national reporting system for Canada $[3,4]$ should be a step forward in assessing rates of LB. However, clinician vigilance, especially in non-endemic areas, is needed for physicians to accurately identify patients suffering from LB when treatment is most likely to be effective [4]. Furthermore, it remains to be seen whether physicians will be as willing to diagnose Lyme if they believe that this diagnosis will receive increased attention and scrutiny as a nationally notifiable disease.

\section{NEW UNDERSTANDING OF LYME BORRELIOSIS ECOLOGY}

In contrast to humans, the dog population of Canada has recently been shown to have a widespread risk of Borrelia infection, as detected by antibody response to the C6 peptide of $B$. burgdorferi [37]. As expected, especially high prevalence of canine LB is found in areas bordering the northeastern United States. In addition to B. burgdorferi, the screening test was conducted to detect Anaplasma phagocytophilum, Ehrlichia canis and Dirofilaria immitis infections in dogs [37]. Borrelia was the most commonly detected of these infections during the year 2008. Ehrlichia canis, which can be vectored by a variety of ticks, was the least prevalent of the four infections nationwide but was the most commonly found pathogen in the western provinces of Alberta and British Columbia [37].

Migratory birds have been an acknowledged part of the disease cycle in Canada since 2001 [38]. Songbirds of an increasing number of species have been demonstrated to disperse ticks across Canada, particularly on the northward migratory flight from the US regions where greater numbers of Borrelia infected ticks are known [38-40]. Rapid establishment of significant levels of $B$. burgdorferi infection in 
Ixodes ticks has been described at a site in Ontario [41] and the authors suggest that birds were the most plausible dispersal agent to this site from the nearest source of infected ticks.

Regional variation in risk of contracting LB may depend on bird migratory patterns. Significant regional variation in the frequency of bird disseminated strains of LB has been demonstrated in the USA [42]. The proportion of birds infested with $I$. scapularis ticks is comparable between regions, however the number of birds infested simultaneously with both larvae and nymphs of $I$. scapularis is greater in the American Midwest. This allows cofeeding between life stages and transmission of $B$. burgdorferi from larval stages to nymphal stages, even for strains of $B$. burgdorferi that do not have a lengthy period of persistence in the host bird. The prevalence of ticks infected with $B$. burgdorferi is also higher in midwestern states than in northeastern states and therefore there is greater potential for bird derived genotypes of $B$. burgdorferi to contribute to the burden of human illness in the Midwest [42]. The province of Manitoba borders the American Midwest and is within the migratory flyway of infected birds, suggesting that bird disseminated risk of human LB in the Canadian province of Manitoba may be greater than the risk of bird disseminated LB in eastern Canadian provinces. Regional variation in bird-tick-mammal cycles of Borrelia infection is significant and much remains to be clarified $[42,43]$.

Genetic variation among strains of Borrelia circulating in Canada, the full range of reservoir species and their dissemination are emerging as important fields of research. Hamer et al [44] explored bird-tick-small mammal cycles in Michigan, which borders Canada's most populous province, Ontario. They found that B. burgdorferi was maintained in both mammals and birds in the apparent absence of I. scapularis, which they suggest implicates the maintenance of $B$. burgdorferi by various species of bird or rabbit ticks as vectors rather than I. scapularis. Strain diversity of B. burgdorferi in ticks dispersed by migratory birds in the northeast USA was recently examined by Mathers et al. [45] who also describe heterogeneity of strains in migratory birds. Rudenko et al. [46] conclude that understanding strain heterogeneity and geographic diversity of subtypes of Borrelia is vital to determining their contribution to human Lyme borreliosis. In Canada, initial results based on Borrelia strains detected by multi locus sequence types (MLSTs) indicate greater diversity of strains than was previously recognized [47]. Since detection of LB has historically been based on the detection of a single strain of $B$. burgdorferi in Canada, increased understanding of the contribution of strain diversity to human infection rates will certainly aid in developing more effective diagnostic methods.

Borrelia garinii, the most neurotropic member of the Borrelia burgdorferi sensu lato species group in Europe, has now also been detected in Canada [48]. Although testing in Canada is restricted to B. burgdorferi strain B31 unless recent travel to Europe has been highlighted, infection with $B$. garinii is possible, especially for hunters, ornithologists and field biologists [49]. Dietrich et al. [49] conclude that the worldwide distribution and diversity of seabird ticks and their associated pathogens has particular relevance for the global epidemiology of tick-borne diseases. Gomez-Diaz et al. [50] state that a greater understanding of the contribution of marine system Borrelia to interactions with terrestrial Borrelia systems will change our view of Borrelia ecology.

\section{IMPROVEMENTS IN TESTING}

In order to improve testing for LB, it is essential to address the ramifications of the fact that the use of commercially available kits for serological testing of strains of Lyme borreliosis in Canadians has generally been limited to detection of B. burgdorferi strain B31 [5]. Furthermore, a positive or equivocal ELISA is needed before the second stage western blot is undertaken [26]. Specific banding patterns on western blots are not reported, which means that the contributions of specific bands remain masked by the words 'positive' or 'negative for antibodies to B. burgdorferi ' [26]. Western blot results with four positive bands rather than the five positive bands required by the US CDC are treated in the same manner as western blots that have no positive bands [26]. Reporting the full banding pattern for western blots would be a significant, and easily accomplished, improvement in testing.

Until recently, concerns over diagnostic sensitivity for diverse strains of $B$. burgdorferi to the C6 peptide ELISA were considered theoretical and inconsequential for detection of North American strains of Lyme borreliosis [51]. However, B. burgdorferi strain N40, originally isolated from a tick in New York [52] and the basis of the first primate model of Lyme borreliosis faithful to the human disease [53], does not reliably react to C6 peptide ELISAs [54]. Unlike strain B31, the vlsE and BBK01 genes of B. burgdorferi strain N40 are on different plasmids and the vlsE locus is significantly different [54]. Since the C6 peptide ELISA is based on the vlsE locus, this implies that serological response to the C6 peptide ELISA may be an underestimate of prevalence of $B$. burgdorferi. Working in Europe with multiple strains of Borrelia, Tjernberg et al. [55] confirmed that C6 peptide ELISAs were unable to reliably detect antibodies for all strains and suggest that combinations of peptides, including IR6 peptides, could address the issue of improvements in testing.

The extensive antigenic shifting of $B$. burgdorferi allows evasion of immune response within even a single host individual. The robust nature of vls antigenic shifting in avoidance of the adaptive immune system in mammals was clarified by Bankhead and Chaconas [56] and further explored by Coutte et al. [57]. This has particular significance for immunoblotting since antigenic variation is part of pathogenhost interactions that are constantly evolving. Immunogenic surface proteins form the basis of the western blot, a required part of a surveillance case of Lyme borreliosis, but antigenic variation is not considered by guidelines produced by the Canadian Public Health Laboratory Network [26].

Coinfections also make LB presentation more variable and their diagnosis more complex [58]. Detection of $B$. burgdorferi is already difficult, and until synergistic infections are identified we will continue to have incomplete understanding of the diagnostic landscape in Canada. Detection of coinfections can be equally as challenging as detection of $B$. burgdorferi, and at present only a narrow subset of the known genotypic diversity of Babesia [59] and Bartonella 
can be readily tested [60]. Expansion of this capacity constitutes another area for potential diagnostic improvement.

Investigation of the full tick microbiome should benefit diagnosis of coinfections by focusing investigation on the key players as well as understanding interaction effects that are not evident when disease causing organisms are considered in isolation. The gold standard for identification of pathogenic bacteria has been to culture the pathogen from affected tissues [61] and yet the number of known microbes for which we have no useful culture techniques has increased. The "great plate count anomaly" [62] refers to the fact that most microbes that have been detected by modern molecular techniques have remained uncultured. Using DNA based diagnostics, it has become clear that culturing ticks before PCR has seriously limited our appreciation of tick infection rates since Borrelia are notoriously difficult to culture [63]. As slow growing bacteria, Borrelia are most easily cultured using selective media with the addition of antibiotics to the culture medium to enhance growth so that Borrelia are not overgrown by faster multiplying bacteria [64,65]. Questions already arose in the late 1980's about the usefulness of culture before the polymerase chain reaction (PCR) [66]. PCR amplification of Borrelia DNA from tick homogenate without prior culturing is now the generally accepted technique to identify Borrelia genospecies, which means that even strains that cannot be cultured may be identified (i.e. [44,47]. The resulting increase in appreciation for the variability of strains in Borrelia means that we have a broader understanding of the possible variants that may be found in Canada [47].

However, in British Columbia (BC), published infection rates of $I$. pacificus ticks continue to be based on their ability to grow in culture [67]. The infection frequencies of less than $1 \%$ that have been reported for BC [67] are much lower than those long known for other areas of Canada, which vary from $15 \%$ in ticks on migratory birds [68] to 60\% at Long Point Ontario, the longest known established area of Lyme endemicity in Canada [69]. In BC, B. bissettii is considered to be nonpathogenic [71] and yet Rudenko et al. [46] have questioned this conclusion and suggest that the BC tickderived strain used in the Schneider et al. study [70] was not directly comparable to the pathogenic rodent-derived strain of $B$. bissettii and that the pathogenic potential of $B$. bissetti may have a greater role in LB than was previously recognized [71].

In eastern Canada, it is assumed that the establishment of reproducing populations of the vector species, I. scapularis, is necessary prior to establishment of B. burgdorferi [68] and modeling efforts have been based on this understanding [72]. Of particular note for the western provinces of Canada, prairie habitat has now been demonstrated to be suitable for maintenance of populations of $I$. scapularis, perhaps even at a level similar to the forested habitats that are often assumed to be the sole suitable habitat for this tick [73]. These authors also caution that small mammals, specifically voles, Microtus ochrogaster, may be an under-appreciated reservoir species for $B$. burgdorferi. Consequently it is essential to employ monitoring approaches that are as free as possible of assumptions about the life cycle and habitat affinities of the vectors of $B$. burgdorferi.
Public health measures for modeling LB in eastern Canada have focused on I. scapularis alone (e.g. [72]). However, the vector list for $B$. burgdorferi is not necessarily restricted to I. scapularis and I. pacificus in Canada. Ixodes angustus is a demonstrated vector of LB [74] with widespread distribution [75]. I. angustus was named as part of a two tick cycle for human infection in BC, based in part on a human case of LB in the neighboring American state of Washington [76]. Even so, Canadian areas of endemicity for B. burgdorferi are officially restricted to areas where I. scapularis and I. pacificus are established, which means that Alberta and northern Canada are absent from consideration for cases of Lyme disease [32,68]. Only in BC has I. angustus been considered in ecological niche modeling of Lyme borreliosis [77].

\section{PROGRESSION TOWARD INCREASINGLY NAR- ROW DIAGNOSTIC STANDARDS}

Historical studies, using clinical diagnoses and retrospective serology, reported Lyme borreliosis in Canada soon after the causative agent was described in the United States [3,7880]. These early cases were diagnosed based on the EM rash, arthritic or neurologic symptoms, and usually involved retrospective positive immunofluorescent antibody (IFA) or ELISA results.

In 1991, a Canadian consensus conference on Lyme disease decided that serologic studies must be interpreted with caution and that both the vector and causative organism were present in only one endemic area, at Long Point in Ontario [81]. The consensus statement emphasized diagnostic reliance on prior identification of areas of endemicity, with the explanation that false-positive results were of great concern in regions of generally low incidence such as Canada [81]. The conference concluded that further research was necessary and that a national reporting system should be established. This conference recognized that Canadian surveillance criteria were more conservative than American criteria. They determined that clinical management of suspected cases should not rely solely on surveillance criteria, but the conference did not establish clinical criteria other than the diagnostic EM rash, which had to be contracted in an area previously identified as endemic. The conference regarded in a positive light the likelihood that serologic methodologies would continue to evolve as new information became available. Up to $30 \%$ of patients were believed to suffer from Herxheimer reactions upon treatment with antibiotics, and post-infectious fatigue syndromes occurred in approximately $15 \%$ of patients [81].

Starting in the 1990's in Canada, human cases of Lyme disease were increasingly diagnosed serologically by relying on the standardized strain B31 (originally isolated from a tick from New York [82]), with western blot interpretations based on the Dearborn criteria favored by the US CDC (e.g. $[11,26]$. However concern was soon voiced over the primarily neurological symptoms, rather than the expected arthritic symptoms, that occurred on the west coast of British Columbia [83]. In Europe, a neurotropic species (B. garinii) as well as a primarily dermatological species (B. afzelii) have been described since 1992 [84], but North America continues to be predominantly regarded as having only one narrowly de- 
fined species that causes primarily arthritic symptoms (e.g. [51]).

In British Columbia, where the vector ticks are Ixodes pacificus and Ixodes angustus [76], a large number of patients were initially being diagnosed by their family physicians as having probable Lyme borreliosis based on the EM rash and positive IFA results. However, the existence of $B$. burgdorferi in BC was questioned in 1992 by Burdge and O'Hanlon, who stressed the likelihood of false positive results [11]. Although nine locations in BC were demonstrated by the British Columbia Centre for Disease Control to be endemic for B. burgdorferi in 1993 [76] a referral centre devoted to studying human cases of possible Lyme borreliosis in British Columbia the same year declared all of BC to be a nonendemic area [85]. The clinic closed when it was concluded that only two of 65 patients had a reasonable probability of having Lyme borreliosis and the two cases of probable Lyme borreliosis were acquired during travel outside British Columbia. The study concluded that in areas of nonendemicity such as British Columbia, physician inexperience commonly led to misdiagnoses of Lyme disease [85]. An over-reactive IFA result was considered to be a clear contributor to misdiagnosis by the referring physician (erratum to [85]. Burdge and O'Hanlon [85] concluded that the main contribution of the $\mathrm{BC}$ clinic would be to support further restriction of serological testing by advocating the use of standardized commercial kits restricting the diagnosis to a narrow definition of Lyme borreliosis. Avoidance of unnecessary antibiotic usage and educating physicians about the extreme improbability of Lyme disease in areas of Canada other than a single area of southern Ontario were also considered major successes of this clinic. However public concern about increasing incidence of Lyme borreliosis was expressed by Kindree in 1994 [86], and the number of regions endemic for $B$. burgdorferi in $\mathrm{BC}$ was expanded to 18 by 1995 [87].

In 2005, The Canadian Journal of Continuing Medical Education published a paper expressing the opinion that the majority of cases of Lyme borreliosis in Canada were selfdiagnosed and based on misinformation gleaned from the internet, with Lyme patient advocacy groups being viewed as serving to exacerbate conflict [88]. These ideas were further developed by Bowie [16], who highlighted general frustrations due to interactions with Lyme disease advocacy groups and concluded that it was unlikely that health issues surrounding Lyme disease could be resolved without an externally-mediated process. On the other hand, Artsob [3] provided a summary of peer-reviewed literature pertinent to public health in Canada that recognized that early cases of Lyme borreliosis in Canada are not well captured in Canadian statistics.

In two 2011 publications for BC, a province recognized by this time as having endemic areas, Henry et al. [24] and Henry and Morshed [67] reported that LB is potentially under reported by as much as $40 \%$. Based on their survey of physician awareness, slightly more than half (57\%) of physicians were aware that the EM rash was sufficient for diagnosis and the presence of the EM rash should trigger prescription of antibiotics at the time of diagnosis [67]. They found that a total of 148 doctors clinically diagnosed 221 cases of
Lyme borreliosis in 2007, at the same time that only 13 cases were reported to provincial authorities. Hundreds of cases of Lyme borreliosis in a known endemic area were therefore not accurately reported to the public.

A second consensus conference for Canada was held in 2006 to expand on the concerns voiced at the 1991 conference [25]. This second conference was unable to achieve consensus on a number of issues, although there was agreement that technical working groups should be established to address the complex issues by examining available scientific literature [25]. To the best of our knowledge, the only public notification of progress on these working groups by July 2011 has been a request in June 2010 for a member of the Association of Medical Microbiology and Infectious Diseases (Canada) to participate in working group on Lyme disease and other tick-borne diseases [89].

\section{SURVEY OF SELF-IDENTIFIED CANADIANS WITH LYME BORRELIOSIS}

In order to establish an independent, data-driven understanding of rates of LB in Canada, as well as to contribute toward finding common ground among the diversity of opinions about LB in Canada, we undertook a survey of Canadians who identify themselves as having LB (referred to as Lyme disease in our survey). The immediate aim was to determine the basis for this self-identification. The survey was distributed in spring 2011 to: 1) an address list of previous email correspondents with the Canadian Lyme Disease Foundation, 2) doctors known to be treating Canadian LB patients (e.g. members of the International Lyme and Associated Diseases Society [90], 3) members of a CanLyme Forum [91] and a CanLyme Facebook group [92] and 5) advertised on the homepage of the CanLyme website [93].

The survey was purely descriptive in nature and included 21 questions that were designed to assess the reasons why respondents believed that they suffered from a LB infection [93]. Questions included a history of symptoms, the clinical and laboratory basis of their diagnosis, the location of presumed exposure, presence of EM rash, coinfection testing and current quality of life. Approval to conduct the survey was granted by the Health Research Ethics board of the University of Alberta in February 2011.

As of July 1, 2011, a total of 110 completed surveys were received from 8 provinces (Table 1). Most of these [71] were from two provinces, BC and Ontario, that are widely recognized as being endemic regions for LB. Alberta, which is not generally recognized as being endemic, had a relatively high rate of respondents compared to Quebec and the Atlantic provinces, which are considered endemic, a pattern that may reflect an ascertainment bias due to the Alberta location of the authors of the study. Most cases (77/101) were reported as probably having been contracted in endemic regions of Ontario, British Columbia or the USA (Table 1). Only 6 of the 21 respondents from Alberta thought that they had been exposed to LB in Alberta, which is more in line with the non-endemic status of that province, but nonetheless indicates that this status may require revision.

Most diagnoses (89/110) of LB in Canada were based on a clinical diagnosis by a medical doctor (Fig. 1). Of these 89 
Table 1. Province of Residence and Likely Location of Exposure to LB by Survey Respondents

\begin{tabular}{|c|c|c|}
\hline Location of Residence & $\begin{array}{c}\text { Number of Respon- } \\
\text { dents }\end{array}$ & Location of Exposure \\
\hline \hline Ontario & 35 & 28 \\
\hline Quebec & 5 & 4 \\
\hline New Brunswick & 1 & 1 \\
\hline Nova Scotia & 2 & 1 \\
\hline BC & 36 & 40 \\
\hline Manitoba & 6 & 3 \\
\hline Saskatchewan & 2 & 6 \\
\hline Alberta & 21 & 9 \\
\hline USA & 2 & 2 \\
\hline Europe & 0 & 9 \\
\hline Central America & 0 & 110 \\
\hline unknown & 0 & \\
\hline total & 110 & 3 \\
\hline
\end{tabular}

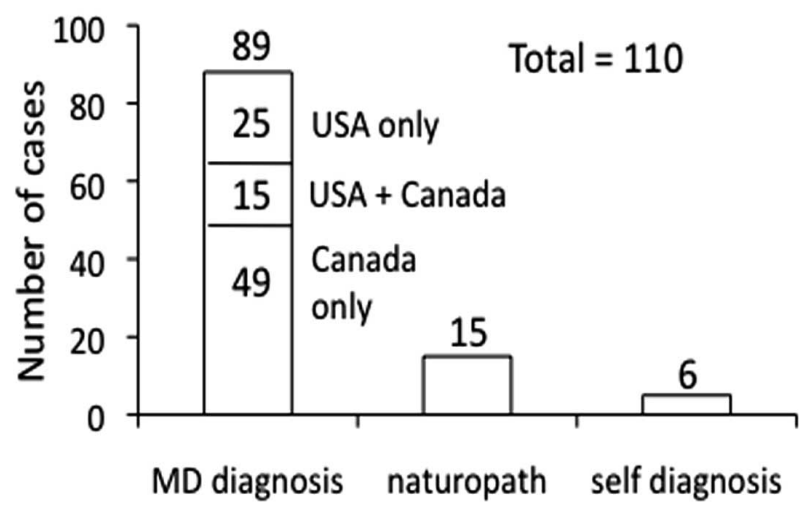

Fig. (1). Basis for self-identification as suffering from Lyme borreliosis.

cases, 15 traveled to the USA for an initial diagnosis later accepted by a Canadian doctor, while 25 received their LB diagnosis only in the USA. Diagnoses by licensed naturopaths comprised 15 of the 110, while only 6 were selfdiagnosed (Fig. 1), which does not support statements that most self-identified cases of LB are based on diagnoses outside of the mainstream medical community $[16,88]$. In addition, respondents generally reported that their quality of life improved once they received the LB diagnosis. Of 89 respondents who received antibiotic treatment, 7 were still early in their treatment period and 75 reported improvement, while 7 reported no improvement in symptoms. For those receiving non-antibiotic (generally herbal) treatment alone, 6 reported improvement and 3 reported no improvement. Four respondents had yet to receive treatment and 8 did not answer the question. Based on this survey, a number of people have received LB diagnoses outside the Canadian medical system, and the great majority of self-identified LB patients have reported improvement in their symptoms once they obtained access to basic treatment that has generally relied on antibiotics.

Coinfections provide a complicating factor for the majority of self-identified LB respondents in our survey (Fig. 2). At least one coinfection was reported by $60 \%(66 / 110)$ of respondents, and of these 16 reported 3 or more coinfections. About half of the coinfections were diagnosed on the basis of lab tests rather than clinical symptoms (Fig. 3), which establishes an independent, objective basis for a substantial proportion of these diagnoses. The most commonly reported coinfections were Bartonella and Babesia species (Fig. 3), while four other genera of microorganisms were present at lower frequencies. Of the four additional groups, it is interesting to note that Anaplasma and Ehrlichia have also been reported as consistent, low-frequency coinfections in dogs that have been diagnosed with LB [37].

Our survey provides evidence that most Canadians who self-identify as having Lyme disease are basing their statement on a diagnosis given to them by a physician. Furthermore, this group has a high incidence of at least one coinfec-

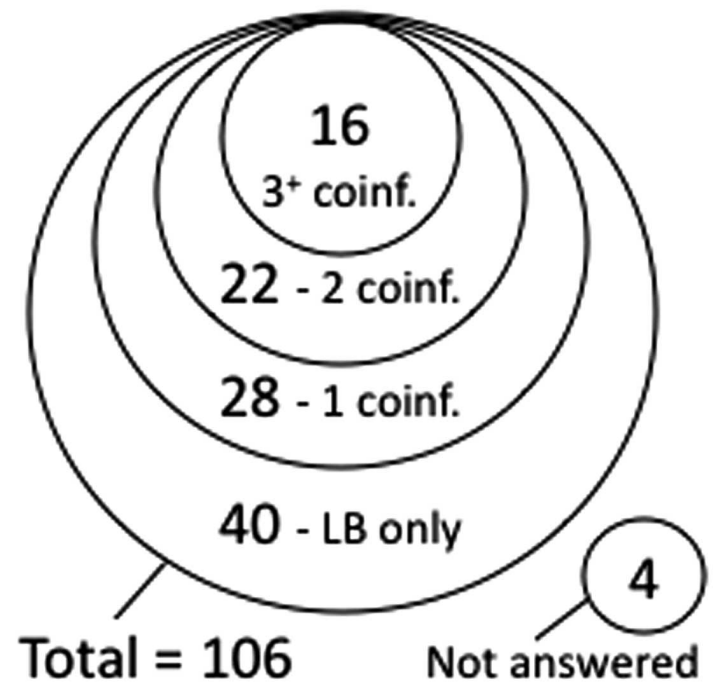

Fig. (2). Frequency of bacterial coinfections with Lyme borreliosis in Canada.

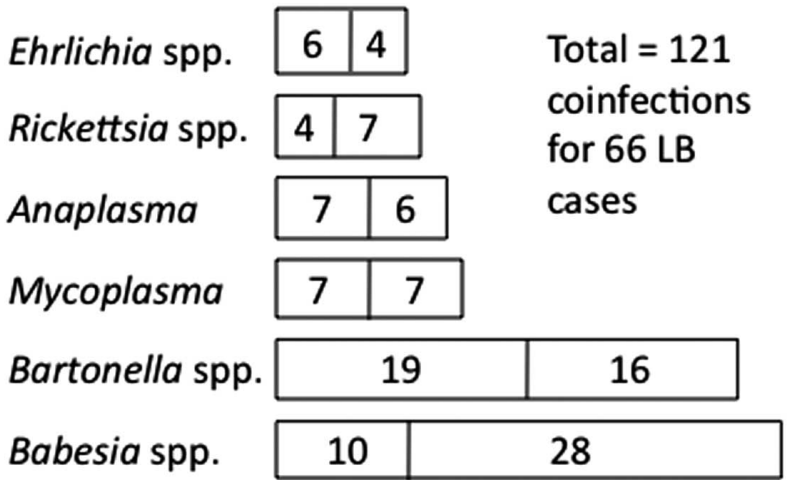

Diagnosis: Lab-based (left) vs clinical (right)

Fig. (3). Basis for diagnosis of coinfections. 
tion, supported by lab tests, which means that they are likely to suffer from a more complex illness than LB alone [58]. Consequently, these data support the need for further awareness of, and research on, the contribution of Lyme borreliosis and its coinfections to the burden of chronic illness in Canada.

\section{BRIDGING THE GAP BETWEEN LOW OFFICIAL LYME BORRELIOSIS RATES AND MEDIA RE- PORTS}

There is no shortage of proposals for solutions to the conflicts surrounding Lyme disease [8,94]. Unfortunately, Canada has until recently relied on a strict and narrow understanding of Lyme borreliosis that was shaped by American research on strains common to the east coast of the USA. However, a vital multiplicity of approaches is available globally to provide guidance and inspiration for improved diagnosis and treatment of Lyme borreliosis. As Genuis [1] has pointed out, "historical precedent repeatedly illustrates that diversity of thought and opinion, dissonance with the status quo, and openness to exploring new ideas are what moves medicine forward." In short, a well-educated populace capable of expressing a diversity of views informed by objective evidence should be part of the solution to any complex challenge. Canada has such a populace, as well as a growing cohort of alternative health care providers including naturopaths, and a strong medical community supported by centralized systems that provide sufficient numbers to perform comparative effectiveness research [95].

In particular, there is high technical potential for improved understanding of variation among strains of Borrelia and coinfections. Open evaluation and synthesis of information from multiple sources including laboratory and clinical approaches, patient advocacy groups and international perspectives will be required, but computing power and analytical methods are no longer a limiting constraint for approaching such complex problems. In addition, there have been improvements in recognizing a variety of diseases that have considerable overlap of symptoms with LB, including chronic fatigue, myalgic encephalomyelitis, fibromyalgia and chronic Lyme disease [46,96].

As an example, newly available techniques for high throughput sequencing will allow genomic analysis of individual patients and tissue samples to better understand the contributions of variation among patients, local environmental factors and synergistic interactions among coinfecting pathogens. A metagenomic approach to the microbial ecology of the tick as well as affected human tissues and an active search for coinfections will create new approaches for diagnosis and treatment. Recognition of the beneficial as well as pathogenic members of the microbial community will allow a greater understanding of the challenges involved in creating more effective and longer term treatments for LB. Integration of classical genomics with the metagenomics approach should allow the diversity of human response to infection to be deciphered.

The government of British Columbia has recently announced plans to fund a study of chronic disease that aims to accurately diagnose, treat and provide ongoing symptom management for these complex conditions [97]. Serious ef- forts are also underway in Ontario to establish a clinic that focuses on Lyme disease research (R. Magnotta, pers. comm.).

Adaptive responses that build on careful evaluation of successful treatments will be crucial for success. Openness to international perspectives and dissemination of effective strategies such as are offered at Deutsche Borreliose Gesellschaft meetings are key to seeing resolution of the conflict that has previously occurred within the history of Lyme borreliosis. Evolutionary approaches such as those described by Nesse and Stearns [98] provide new perspectives and practical suggestions for how to advance our understanding of this complex disease.

\section{CONCLUSIONS/SUMMARY}

An international and transcontinental perspective on LB is needed to better understand the complexity of this disease as it currently exists in Canada. With diagnostic options narrowly focused on those appropriate to the eastern USA, Canadian patients have been restricted in their access to health care. Development of better testing and emphasis on patient outcomes is needed, including more opportunity for adaptive approaches and more comprehensive documentation of outcomes. Such conditions allow better clinical diagnoses and treatments that take into account the diversity of Borrelia genotypes as well as their coinfections and regionally variable ecological circumstances. These improvements are particularly important in the context of government funded healthcare where avoidance of chronic illness is more consciously tied to broader economic as well as societal benefits.

Difficult-to-diagnose diseases are not only a challenge to our current paradigms for medical research and administration. Much is at stake in resolving such problems, since successful public healthcare is considered by many Canadians to be a defining characteristic of the Canadian state [99]. Consequently, Lyme patients who abandon the Canadian medical system are a sign of a fundamental incompatibility between their perceived needs and what the current Canadian system provides, and in doing so they are part of the thin edge of a wedge that may alter this system in fundamental ways. Successful resolution of these conflicts will depend on action by both patients and physicians, ideally via cooperation rather than conflict. But for hundreds and perhaps thousands of Canadians the means matter less than the desired endpoint, which is timely treatment and effective care for people who suffer from the debilitating conditions that characterize Lyme borreliosis.

\section{CONFLICT OF INTEREST}

The authors confirm that this article content has no conflicts of interest.

\section{ACKNOWLEDGEMENTS}

We are grateful to Dr. Judith Miklossy for inviting us to participate in a symposium of the Deutsche Borreliose Gesellschaft, for moral support and access to communications lists from the Canadian Lyme Disease Foundation, and for 
funding support to prepare this manuscript from an NSERC Discovery Grant to F. Sperling.

\section{REFERENCES}

[1] Genuis SJ. Dismembering the ethical physician. Postgrad Med J 2006; 82(966): 233-8.

[2] Groopman JE. How doctors think : Boston: Houghton Mifflin Co 2007.

[3] Artsob H. NCCID Purple Paper. Canada: National Collaborating Centre for Infectious Diseases 2010; p. 17.

[4] Ogden NH, Lindsay LR, Morshed M, Sockett PN, Artsob H. The emergence of Lyme disease in Canada. CMAJ 2009; 180(12): 1221-4.

[5] Sperling JLH, Sperling FAH. Lyme borreliosis in Canada: biological diversity and diagnostic complexity from an entomological perspective. Can Entomol 2009; 141: 521-49.

[6] Association of Medical Microbiology and Infectious Disease. CTV W5 Story - Lyme disease Debate. 2009; Available at: http: //www.ammi.ca/media-centre/archived-press-releases/archived2009. [Accessed 11th July 2011]

[7] BC Ministry of Health. B.C.'s Lyme testing meets international standards. 2010; Available at: http: //datafind.gov.bc.ca/query.html?qp=\&style=ftr\&qt=lyme\&Submit. $\mathrm{x}=0$ \&Submit. $\mathrm{y}=0$. [Accessed 11th July 2011].

[8] Ferrie H. Ending denial: the Lyme Disease epidemic : a Canadian public health disaster : a call for action from patients, doctors, researchers, and politicians. Caledon, ON.: Kos Pub. 2010.

[9] Canadian Broadcasting Corportation. Group gathers on Hill, looks for Lyme disease help. 2007; Available at: http: //www.cbc.ca/ news/canada/ottawa/story/2007/09/14/lymedisease-awareness.html. [Accessed 16th July, 2011]

[10] Zoomer radio. Lyme Disease Awareness. 2011; Available at: http: //zoomerradio.ca/dale-goldhawk/tag/lyme-disease/. [Accessed 11th July 2011].

[11] Burdge DR, OHanlon D. Lyme disease: review from a Canadian perspective. Can Fam Physician 1992; 38: 1426-32.

[12] Donta ST. Late and chronic Lyme disease. Med Clin North Am 2002; 86(2): 341-9, vii.

[13] Cameron DJ. Proof that chronic Lyme disease exists. Interdiscip Perspect Infect Dis 2010; 2010: 876450.

[14] Wormser GP, Dattwyler RJ, Shapiro ED, et al. The clinical assessment, treatment, and prevention of lyme disease, human granulocytic anaplasmosis, and babesiosis: clinical practice guidelines by the Infectious Diseases Society of America. Clin Infect Dis 2006; 43(9): 1089-134.

[15] Baker PJ. Chronic Lyme disease: in defense of the scientific enterprise. FASEB J 2010; 24(11): 4175-7.

[16] Bowie WR. Guidelines for the management of lyme disease : the controversy and the quandary. Drugs 2007; 67(18): 2661-6.

[17] Ogden NH, Artsob H, Lindsay LR, Sockett PN. Lyme disease: A zoonotic disease of increasing importance to Canadians. Can Fam Physician 2008; 54(10): 1381-4.

[18] Ontario Ministry of Health and Long-Term Care. Let's target Lyme - Lyme Disease - Information for health care professionals. 2011; Available at: http: //www.health.gov.on.ca/en/ms/lyme/pro/ [Accessed 11th July 2011].

[19] Public Health Agency of Canada. Integrated strategy on healthy living and chronic disease. 2005; Available at: http: //www.phacaspc.gc.ca/media/nr-rp/2005/2005_37bk1-eng.php [Accessed 11th July 2011].

[20] Charron DF, Sockett PN. Signs of change, signs of trouble. 2005; Available at: http: //www.hc-sc.gc.ca/sr-sr/pubs/hprrpms/bull/2005-climat/index-eng.php. [Accessed 11th July 2011].

[21] Bacon RM, Kugeler KJ, Griffith KS, Mead PS. Lyme Disease --United States, 2003--2005. 2007; Available at: http: //www.cdc. gov/mmwr/preview/mmwrhtml/mm5623a1.htm [Accessed 11th July 2011].

[22] Public Health Agency of Canada. Lyme Disease Fact Sheet. 2010; Available at: http: //www.phac-aspc.gc.ca/id-mi/lyme-fs-eng.php. [Accessed 11th July 2011].

[23] Lyme disease in Canada: Q \& A for paediatricians. Can J Infect Dis Med Microbiol 2009; 20(2): 42-4.

[24] Henry B, Roth D, Reilly R, et al. How big is the lyme problem? using novel methods to estimate the true number of lyme disease cases in british columbia residents from 1997 to 2008. Vector Borne Zoonotic Dis 2011; 11(7): 863-8.

[25] National Lyme Disease Meeting, March 8-9, 2006. Toronto, ON Canada. 2008; Available at: http: //www.phac-aspc.gc.ca/idmi/lyme032006-eng.php [Accessed 11th July 2011].

[26] Canadian Public Health Laboratory Network. The laboratory diagnosis of Lyme borreliosis: guidelines from the Canadian Public Health Laboratory Network. Can J Infect Dis Med Microbiol 2007; 18(2): 145-8.

[27] Racine R, McLaughlin M, Jones DD, et al. IgM production by bone marrow plasmablasts contributes to long-term protection against intracellular bacterial infection. J Immunol 2011; 186(2): 1011-21.

[28] Centers for Disease Control and Prevention (CDC). Lyme Disease (Borrelia burgdorferi) 2008 Case Defintion. 2008; Available at: http: //www.cdc.gov/osels/ph_surveillance/nndss/casedef/lyme_ disease_2008.htm. [Accessed 12th July 2011].

[29] Centers for Disease Control and Prevention (CDC). Lyme Disease (Borrelia burgdorferi) 2011 Case Defintion. 2011; Available at: http: //www.cdc.gov/osels/ph_surveillance/nndss/casedef/lyme_ disease_Current.htm [Accessed 12th July 2011].

[30] Government of Nova Scotia. Nova Scotia Communicable Disease Control Manual. 2003; Available at: http: //www.gov.ns.ca/hpp/ cdpc/info-for-professionals.asp. [Accessed 13th July 2011].

[31] Government of Ontario. Appendix B: Provincial Case Defintions for Reportable Diseases: Disease: Lyme Disease. 2009; Available at: http: //www.health.gov.on.ca/english/providers/program/pubhealth/oph_standards/ophs/infdispro.html\#l. [Accessed $13^{\text {th }}$ July, 2011].

[32] Government of Alberta. Alberta Health and Wellness: Public Health Notifiable Disease Management Guidelines: Lyme Disease. 2011; Available at: http: //www.health.alberta.ca/professionals/ casedefinitions-manual.html. [Accessed 13th July 2011].

[33] Public Health Agency of Canada. Lyme disease 2008; Available at: http: //www.phac-aspc.gc.ca/publicat/ccdr-rmtc/09vol35/35s2/ Lymeeng.php. [Accessed 15th July 2011].

[34] Makhani N, Morris SK, Page AV, et al. A twist on Lyme: the challenge of diagnosing European Lyme neuroborreliosis. J Clin Microbiol 2011 Jan; 49(1): 455-457.

[35] Mygland A, Ljostad U, Fingerle V, et al. EFNS guidelines on the diagnosis and management of European Lyme neuroborreliosis. Eur J Neurol 2010; 17(1): 8-16, e1-4.

[36] National Microbiology Laboratory Guide to Services. 2009; Available at: http: //www.nml-lnm.gc.ca/guide2/labsview.php?labID= 21. [Accessed 12th July 2011].

[37] Villeneuve A, Goring J, Marcotte L, Overvelde S. Seroprevalence of Borrelia burgdorferi, Anaplasma phagocytophilum, Ehrlichia canis, and Dirofilaria immitis among dogs in Canada. Can Vet J 2011; 52: 527-30.

[38] Scott JD, Fernando K, Banerjee SN, et al. Birds disperse ixodid (Acari: Ixodidae) and Borrelia burgdorferi-infected ticks in Canada. J Med Entomol 2001; 38(4): 493-500.

[39] Morshed MG, Scott JD, Fernando K, et al. Migratory songbirds disperse ticks across Canada, and first isolation of the Lyme disease spirochete, Borrelia burgdorferi, from the avian tick, Ixodes auritulus. J Parasitol 2005; 91(4): 780-90.

[40] Scott JD, Lee MK, Fernando K, et al. Detection of Lyme disease spirochete, Borrelia burgdorferi sensu lato, including three novel genotypes in ticks (Acari: Ixodidae) collected from songbirds (Passeriformes) across Canada. J Vector Ecol 2010; 35(1): 124-39.

[41] Scott JD, Lee MK, Fernando K, Jorgensen DR, Durden LA, Morshed MG. Rapid introduction of Lyme disease spirochete, Borrelia burgdorferi sensu stricto, in Ixodes scapularis (Acari: Ixodidae) established at Turkey Point Provincial Park, Ontario, Canada. J Vector Ecol 2008; 33(1): 64-9.

[42] Brinkerhoff RJ, Folsom-O'Keefe CM, Streby HM, Bent SJ, Tsao K, Diuk-Wasser MA. Regional variation in immature Ixodes scapularis parasitism on North American songbirds: implications for transmission of the Lyme pathogen, Borrelia burgdorferi. J Med Entomol 2011; 48(2): 422-8.

[43] Brinkerhoff RJ, Folsom-O'Keefe CM, Tsao K, Diuk-Wasser MA. Do birds affect Lyme disease risk? Range explansion of the vectorborne pathogen Borrelia burgdorferi. Front Ecol Environ 2011; 9(2): 103-10. 
[44] Hamer SA, Hickling GJ, Sidge JL, Rosen ME, Walker ED, Tsao JI. Diverse Borrelia burgdorferi strains in a bird-tick cryptic cycle. Appl Environ Microbiol 2011; 77(6): 1999-2007.

[45] Mathers A, Smith RP, Cahill B, et al. Strain diversity of Borrelia burgdorferi in ticks dispersed in North America by migratory birds. J Vector Ecol 2011; 36(1): 24-9.

[46] Rudenko N, Golovchenko M, Grubhoffer L, Oliver JHJ. Updates on Borrelia burgdorferi sensu lato complex with respect to public health. Ticks Tick-Borne Dis 2011 [EPub ahead of Print]

[47] Ogden NH, Margos G, Aanensen DM, et al. Investigation of genotypes of Borrelia burgdorferi in Ixodes scapularis ticks collected during surveillance in Canada. Appl Environ Microbiol 2011; 77(10): 3244-54.

[48] Smith RP Jr, Muzaffar SB, Lavers J, et al. Borrelia garinii in seabird ticks (Ixodes uriae), Atlantic Coast, North America. Emerging Infect Dis 2006; 12(12): 1909-12.

[49] Dietrich M, Gomez-Diaz E, McCoy KD. Worldwide distribution and diversity of seabird ticks: implications for the ecology and epidemiology of tick-borne pathogens. Vector Borne Zoonotic Dis 2011; 11(5): 2453-70.

[50] Gomez-Diaz E, Boulinier T, Sertour N, Cornet M, Ferquel E, McCoy KD. Genetic structure of marine Borrelia garinii and population admixture with the terrestrial cycle of Lyme borreliosis. Environ Microbiol 2011; 13(9): 2453-67.

[51] Wormser GP, Liveris D, Hanincova K, et al. Effect of Borrelia burgdorferi genotype on the sensitivity of C6 and 2-tier testing in North American patients with culture-confirmed Lyme disease. Clin Infect Dis 2008; 47(7): 910-14.

[52] Barthold SW, Moody KD, Terwilliger GA, Jacoby RO, Steere AC. An animal model for Lyme arthritis. Ann N Y Acad Sci 1988; 539 : 264-73.

[53] Pachner AR, Delaney E, O'Neill T, Major E. Inoculation of nonhuman primates with the N40 strain of Borrelia burgdorferi leads to a model of Lyme neuroborreliosis faithful to the human disease. Neurology 1995; 45(1): 165-72.

[54] Tunev SS, Hastey CJ, Hodzic E, Feng S, Barthold SW, Baumgarth N. Lymphoadenopathy during Lyme borreliosis is caused by spirochete migration-induced specific B cell activation. PLoS Pathog 2011; 7(5): e1002066.

[55] Tjernberg I, Sillanpaa H, Seppala I, Eliasson I, Forsberg P, Lahdenne P. Antibody responses to borrelia IR(6) peptide variants and the C6 peptide in Swedish patients with erythema migrans. Int J Med Microbiol 2009; 299(6): 439-46.

[56] Bankhead T, Chaconas G. The role of VlsE antigenic variation in the Lyme disease spirochete: persistence through a mechanism that differs from other pathogens. Mol Microbiol 2007; 65: 1547-58.

[57] Coutte L, Botkin DJ, Gao L, Norris SJ. Detailed analysis of sequence changes occurring during vlsE antigenic variation in the mouse model of Borrelia burgdorferi infection. PLoS Pathog 2009; 5(2): e1000293.

[58] Swanson SJ, Neitzel D, Reed KD, Belongia EA. Coinfections acquired from ixodes ticks. Clin Microbiol Rev 2006; 19(4): 70827.

[59] Leiby DA. Transfusion-transmitted Babesia spp.: bull's-eye on Babesia microti. Clin Microbiol Rev 2011; 24(1): 14-28.

[60] Breitschwerdt EB, Maggi RG, Chomel BB, Lappin MR. Bartonellosis: an emerging infectious disease of zoonotic importance to animals and human beings. J Vet Emerg Crit Care (San Antonio) 2010; 20(1): 8-30.

[61] Weinstein MP. Blood culture contamination: persisting problems and partial progress. J Clin Microbiol 2003; 41(6): 2275-8.

[62] Staley JT, Konopka A. Measurement of in situ activities of nonphotosynthetic microorganisms in aquatic and terrestrial habitats. Annu Rev Microbiol 1985; 39: 321-46.

[63] Biskup UG, Strle F, Ruzic-Sabljic E. Loss of plasmids of Borrelia burgdorferi sensu lato during prolonged in vitro cultivation. Plasmid 2011; 66(1): 1-6.

[64] Johnson SE, Klein GC, Schmid GP, Bowen GS, Feeley JC, Schulze T. Lyme disease: a selective medium for isolation of the suspected etiological agent, a spirochete. J Clin Microbiol 1984; 19(1): 81-2.

[65] Morshed MG, Konishi H, Nishimura T, Nakazawa T. Evaluation of agents for use in medium for selective isolation of Lyme disease and relapsing fever Borrelia species. Eur J Clin Microbiol Infect Dis 1993; 12(7): 512-8.
[66] Persing DH, Telford SR,3rd, Spielman A, Barthold SW. Detection of Borrelia burgdorferi infection in Ixodes dammini ticks with the polymerase chain reaction. J Clin Microbiol 1990; 28(3): 566-72.

[67] Henry B, Morshed M. Lyme disease in British Columbia: are we really missing an epidemic? B C Med J 2011; 53(5): 224-9.

[68] Ogden NH, Lindsay LR, Morshed M, Sockett PN, Artsob H. The rising challenge of Lyme borreliosis in Canada. Can Commun Dis Rep 2008; 34(1): 1-19.

[69] Public Health Agency of Canada. Ticks and Lyme Disease. 2010; Available at: http: //www.phac-aspc.gc.ca/id-mi/tickinfo-eng.php. [Accessed $11^{\text {th }}$ July, 2011].

[70] Schneider BS, Schriefer ME, Dietrich G, Dolan MC, Morshed MG Zeidner NS. Borrelia bissettii isolates induce pathology in a murine model of disease. Vector Borne Zoonotic Dis 2008; 8(5): 623-33.

[71] Girard YA, Fedorova N, Lane RS. Genetic diversity of Borrelia burgdorferi and detection of $\mathrm{B}$. bissettii-like DNA in serum of north-coastal California residents. J Clin Microbiol 2011; 49(3): 945-54.

[72] Ogden NH, Bouchard C, Kurtenbach K, et al. Active and passive surveillance and phylogenetic analysis of Borrelia burgdorferi elucidate the process of Lyme disease risk emergence in Canada. Environ Health Perspect 2010; 118(7): 909-14.

[73] Rydzewski J, Mateus-Pinilla N, Warner RE, Hamer S, Weng HY. Ixodes scapularis and Borrelia burgdorferi among diverse habitats within a natural area in east-central Illinois. Vector Borne Zoonotic Dis 2011; 11(10): 1351-8.

[74] Eisen L, Lane RS. Vectors of Borrelia burgdorferi sensu lato. In: Gray J, Kahl O, Lane RS, Stanek G, Eds. Lyme borreliosis: biology, epidemiology and control New York: CABI Publishing 2002.

[75] Durden LA, Keirans JE. Nymphs of the genus Ixodes (Acari: Ixodidae) of the United States: taxonomy, identification key, distribution, hosts, and medical/veterinary importance. Lanham, Maryland: Entomological Society of America 1996

[76] Banerjee SN. Isolation of Borrelia burgdorferi in British Columbia. Can Commun Dis Rep 1993; 19(24): 204-5.

[77] Mak S, Morshed M, Henry B. Ecological niche modeling of lyme disease in British Columbia, Canada. J Med Entomol 2010; 47(1): 99-105.

[78] Bollegraaf E. Lyme disease in Canada. Can Dis Wkly Rep 1988; 14(22): 95-7.

[79] Doby JM, Anderson JF, Couatarmanac'h A, Magnarelli LA, Martin A. Lyme disease in Canada with possible transmission by an insect. Zentralbl Bakteriol Mikrobiol Hyg A 1987; 263(3): 488-90.

[80] Lycka BA. Lyme disease in Canada? CMAJ 1986; 134(1): 48-9.

[81] Consensus conference on Lyme disease. CMAJ 1991; 144(12): 1627-32.

[82] Johnson RC, Schmid GP, Hyde FW, Steigerwalt AG, Brenner DJ. Borrelia burgdorferi sp. nov.: Etiologic agent of Lyme disease. Int J Syst Bacteriol 1984; 34(4): 496-7

[83] LeBourdais E. Activists decry physician disinterest in Lyme disease during Vancouver conference. CMAJ 1995; 153(6): 822-4.

[84] Welsh J, Pretzman C, Postic D, Saint Girons I, Baranton G, McClelland M. Genomic fingerprinting by arbitrarily primed polymerase chain reaction resolves Borrelia burgdorferi into three distinct phyletic groups. Int J Syst Bacteriol 1992; 42(3): 370-7.

[85] Burdge DR, O'Hanlon DP. Experience at a referral center for patients with suspected Lyme disease in an area of nonendemicity: first 65 patients. Clin Infect Dis 1993; 16(4): 558-60.

[86] Kindree D. Borrelia burgdorferi isolated in British Columbia. Clin Infect Dis 1994; 18(5): 844.

[87] Banerjee SN, Banerjee M, Fernando K, Dong MY, Smith JA, Cook D. Isolation of Borrelia burgdorferi, the Lyme disease spirochete, from rabbit ticks, Haemaphysalis leporispalustris--Alberta. Can Commun Dis Rep 1995; 21(10): 86-8.

[88] Forward KR. Lyme disease: dispelling the myth. Can J CME 2005; 17: 73-5.

[89] Association of Medical Microbiology and Infectious Diseases. AMMI Canada Members on External Committees. 2011; Available at: http: //www.ammi.ca/about-ammi-canada/committees. [15 July, 2011].

[90] International Lyme and Associated Diseases Society. 2011; Available at: http: //www.ilads.org/. [16 ${ }^{\text {th }}$ July, 2011].

[91] Canadian Lyme Disease Foundation Bulletin Board Forum Index. 2011. Available at: http: //www.canlyme.com/foum/ [Accessed $15^{\text {th }}$ July, 2011]. 
[92] Canadian Lyme Disease Foundation 2011; Available at: http: //www.facebook.com/pages/Canadian-Lyme-Disease-

Foundation/143033619666?sk=info. [Accessed 15 ${ }^{\text {th }}$ July, 2011].

[93] Canadian Lyme Disease Foundation 2011; Available at: http: //www.canlyme.com/. [Accessed $16^{\text {th }}$ July, 2011].

[94] Institute of Medicine. Critical Needs and Gaps in Understanding Prevention, Amelioration, and Resolution of Lyme and Other Tickborne Diseases: The Short-term and Long-term Ourcomes- Workshop Report. 2011; Available at: http: //www.iom.edu/Reports/ 2011/Critical-Needs-and-Gaps-in-Understanding-Prevention-Amelioration-and-Resolution-of-Lyme-and-Other-Tick-Borne-Diseases. aspx [Accessed $16^{\text {th }}$ July, 2011].
[95] Begley S. The best medicine: Cutting health costs with comparative effectiveness research. Sci Am 2011; 305(1): 50-5.

[96] Carruthers BM. Definitions and aetiology of myalgic encephalomyelitis: how the Canadian consensus clinical definition of myalgic encephalomyelitis works. J Clin Pathol 2007; 60(2): 117-9.

[97] BC Ministry of Health. Help for patients with complex chronic diseases. 2011; Available at: http: //search.news.gov.bc.ca/Default. aspx?keyword=lyme\&x $=0 \& y=0$ [cited: $30^{\text {th }}$ March, 2011]

[98] Nesse RM, Stearns SC. The great opportunity: Evolutionary applications to medicine and public health. Evol Appl 2008; 1(1): 28-48.

[99] Soroka SN. Canadian perceptions of the health care system: A report to the Health Council of Canada. Canada: McGill University 2007.

(c) Sperling et al.; Licensee Bentham Open.

This is an open access article licensed under the terms of the Creative Commons Attribution Non-Commercial License (http://creativecommons.org/licenses/by-nc/3.0/) which permits unrestricted, non-commercial use, distribution and reproduction in any medium, provided the work is properly cited. 